\title{
Examining Opioid Overdose Data in Atlantic County: A Descriptive Case Study
}

\section{By Merydawilda Colon, Ph.D., LSW; Tara Crowell, Ph.D.; Mary Lou Galantino, PT, MS, PhD, MSCE, FAPTA; Carra Leah Hood, Ph.D; and Manish Madan, Ph.D.}

DOI: http://dx.doi.org/10.14713/njs.v5i1.170

Between 2015-2017, local police, state troopers and emergency medical personnel in Atlantic County, NJ collected data on opioid overdose victims within the County. Forms on 311 overdose victims were ultimately completed. Early in 2018, a partnership between the Atlantic County Prosecutor's Office and Stockton University was formed in order to analyze this information and better understand Atlantic County's opioid overdose statistics. Results painted a picture of who is using, and showed that quick response to opioid overdoses and prompt administration of the drug naloxone can save lives. Recommendations for the future include collecting additional data points for overdose victims going forward to allow for deeper study, along with increased distribution of naloxone. Such recommendations can positively contribute to future educational and prevention efforts.

\section{Introduction}

Opioid prescribing rates in the United States elevated and leveled off from 2010-2012 and have reduced since 2012, however, the amount of opioids in morphine milligram equivalents (MME) prescribed remains three times higher than it was in $1999 .{ }^{1}$ In 2017 , an estimated 18 million people had misused medications at least once in the past year. ${ }^{2}$ Also, according to results from the 2017 National Survey on Drug Use and Health, approximately 2 million Americans inappropriately used prescription pain relievers within the past year. This abuse is leading to record

\footnotetext{
${ }^{1}$ Centers for Disease Control and Prevention. Vital Signs: Changes in Opioid Prescribing in the United States, 2006-2015. MMWR 2017; 66(26):697-704.

${ }^{2}$ Center for Behavioral Health Statistics and Quality. Results from the 2017 National Survey on Drug Use and Health: Detailed Tables. Rockville (MD): SAMHSA; 2018. https://www.samhsa.gov/data/report/2017-nsduhdetailed-tables. Accessed June 16, 2019.
} 
numbers of opioid-related overdoses. ${ }^{3}$ In the state of NJ, statistics from 2016 indicate that there were 1,409 opioid-related overdose deaths in the state (for a rate of 16 deaths per 100,000 persons, compared with the national rate of 13.3 deaths per 100,000). ${ }^{4}$ It is clear that opioid overdose deaths have created a public health crisis for the nation as a whole, and the state of NJ in particular. The drug naloxone, a lifesaving medication that can reverse the effects of an opioid overdose, has become the most effective harm reduction tool to curb many of these deaths. ${ }^{5}$

In an attempt to better understand the opioid crisis, and, hopefully, better combat it, between 2015-2017 local police, state troopers, and emergency medical personnel in Atlantic County, NJ collected data on opioid overdose victims in the County. Forms on 311 overdose victims were completed. (Methodology is discussed in greater detail later in the text.) In the fall of 2017, with 3 years of unanalyzed data, the Atlantic County Prosecutor's office approached Stockton University to form a community partnership. The goal for this partnership was to gain a better understanding of the opioid overdoses during this period. As stated in Loretta Jones and Kenneth Wells, "Strategies for Academic and Clinician Engagement in Community-Participatory Partnered Research," 6 experts recommend this type of public participation and the engagement of diverse communities in research as a strategy to enhance its relevance and to address disparities more effectively. ${ }^{7}$ Research indicates that such community-based participatory research (CBPR)

\footnotetext{
${ }^{3}$ Opioid overdose occurs when a person has excessive unopposed stimulation of the opiate pathway. This can lead to decreased respiratory effort and possible fatal outcomes.

${ }^{4}$ National Institute on Drug Abuse, "New Jersey Opioid Summary," February 28, 2018, https://www.drugabuse.gov/drugs-abuse/opioids/opioid-summaries-by-state/new-jersey-opioid-summary.

${ }^{5}$ Chloe J. Jordan et al., "Progress in Agonist Therapy for Substance Use Disorders: Lessons Learned from Methadone and Buprenorphine," Neuropharmacology, April 19, 2019.

${ }^{6}$ Loretta Jones and Kenneth Wells, "Strategies for Academic and Clinician Engagement in CommunityParticipatory Partnered Research," JAMA 297, no. 4 (January 24, 2007): 407-10, https://doi.org/10.1001/jama.297.4.407.

7 "Promoting Health: Intervention Strategies from Social and Behavioral Research," American Journal of Health Promotion 15, no. 3 (January 1, 2001): 149-66, https://doi.org/10.4278/0890-1171-15.3.149.; Sean R. Tunis, Daniel B. Stryer, and Carolyn M. Clancy, "Practical Clinical Trials: Increasing the Value of Clinical Research for Decision
} 
is the prevailing paradigm to facilitate these goals by promoting mutual transfer of expertise and power sharing in decision making and data ownership across community and academic partners. ${ }^{8}$ In other words, it was hoped that combining law enforcement and academic resources and perspectives would allow a more comprehensive analysis of the opioid crisis in Atlantic County.

The Atlantic County Prosecutor's Office/Stockton University team poured over descriptive statistics about opioid overdose victim demographics, the number of overdoses that occurred during the period of study, the response time of first responders, and the victims' responsiveness to treatment with naloxone. The team studied information about overdoses by month, and the locations where overdoses occurred. Who was overdosing? Where and when were overdoes occurring? Were there any patterns? What might be done to decrease drug use, the number of overdoses, and fatalities?

\section{Background}

The persistent opioid epidemic has claimed more than a quarter million American lives over the past several decades. ${ }^{9}$ The epidemic began with an increase of prescription opioid deaths and has now evolved to include secondary impacts of illicit fentanyl and heroin deaths (as when prescription drugs cannot be obtained, these are often substituted). At the same time, deaths due

Making in Clinical and Health Policy," JAMA 290, no. 12 (September 24, 2003): 1624-32, https://doi.org/10.1001/jama.290.12.1624.; ${ }^{7}$ Elias A. Zerhouni, "Translational and Clinical Science--Time for a New Vision," The New England Journal of Medicine 353, no. 15 (October 13, 2005): 1621-23, https://doi.org/10.1056/NEJMsb053723.

${ }^{8}$ Barbara A. Israel et al., eds., Methods for Community-Based Participatory Research for Health, 2nd edition (San Francisco, CA: Jossey-Bass, 2012).; Meredith Minkler and Nina Wallerstein, eds., Community-Based Participatory Research for Health: From Process to Outcomes, 2nd edition (San Francisco, CA: Jossey-Bass, 2008).; M. Viswanathan et al., "Community-Based Participatory Research: Assessing the Evidence," Evidence Report/Technology Assessment (Summary), no. 99 (August 2004): 1-8.

${ }^{9}$ Lawrence Scholl et al., "Drug and Opioid-Involved Overdose Deaths — United States, 2013-2017," MMWR. Morbidity and Mortality Weekly Report 67, no. 5152 (December 21, 2018), https://doi.org/10.15585/mmwr.mm675152e1. 
to prescription opioid overdoses are still increasing. ${ }^{10}$ Data released by the Drug Enforcement Agency (DEA) and the Centers for Disease Control and Prevention (CDC) indicate that from 2001 through 2010, the rate of opiate diversion, prescriptions for opiates, and opiate-related deaths have exponentially increased in the United States. The rates plateaued from 2011 through 2013 but again spiked from 2013 to 2014. ${ }^{11}$ This may not wane anytime soon, as one in six young adults admit to taking prescription medication not prescribed to them. ${ }^{12}$

Experts in pain management believe that the high number of opiate overdoses are not intentional but rather the result of patients legitimately trying to manage unrelenting pain. ${ }^{13}$ The nation has an over prescription problem. Most individuals suffering from low back pain, for example, are prescribed opioids despite no drastic benefit relative to being prescribed a nonaddictive nonsteroidal anti-inflammatory drugs (NSAID). Furthermore, patients who are prescribed opioids for chronic pain and suffer an overdose are almost always placed back on prescription opioids. ${ }^{14}$ Thus, the frequency of opioid overdose continues to increase. Drug overdose is the leading cause of accidental death in the United States and the CDC currently estimates more than 1,000 emergency department visits daily related to the misuse of opioids and about 91 opioid overdose deaths every day. ${ }^{15}$

\footnotetext{
${ }^{10}$ Robert J. Blendon and John M. Benson, "The Public and the Opioid-Abuse Epidemic," The New England Journal of Medicine; Boston 378, no. 5 (February 1, 2018): 407-11, http://dx.doi.org.ezproxy.stockton.edu/10.1056/NEJMp1714529.

${ }^{11}$ Jr Van Demark, Peter Chang, and Daniel Heinemann, "Opioid Analgesics for Chronic Non-Cancer Pain: A Guideline on Opioid Prescribing," South Dakota Medicine: The Journal of the South Dakota State Medical Association No (January 1, 2016): 19.

${ }^{12}$ Lynn R. Webster, "Risk Factors for Opioid-Use Disorder and Overdose," Anesthesia and Analgesia 125, no. 5 (November 1, 2017): 1741-48, https://doi.org/10.1213/ANE.0000000000002496.

${ }^{13}$ Deborah Dowell, Tamara M. Haegerich, and Roger Chou, "CDC Guideline for Prescribing Opioids for Chronic Pain--United States, 2016,” JAMA 315, no. 15 (April 19, 2016): 1624-45, https://doi.org/10.1001/jama.2016.1464.

${ }^{14}$ Joanna G. Katzman et al., "An Innovative Model for Naloxone Use Within an OTP Setting: A Prospective Cohort Study," Journal of Addiction Medicine 12, no. 2 (April 2018): 113-18, https://doi.org/10.1097/ADM.0000000000000374.

${ }^{15}$ Dowell, Haegerich, and Chou, "CDC Guideline for Prescribing Opioids for Chronic Pain--United States, 2016."
} 
In response to these startling statistics, the $\mathrm{CDC}$ moved to limit opioid prescribing by releasing opioid prescribing guidelines for chronic noncancerous pain in March 2016. The guidelines represent a logical and timely federal response to this growing crisis. If fewer opioids are prescribed, perhaps fewer people will become addicted.

An overview of the literature denotes that the primary users of illicit opioids overall are unemployed Caucasian males. ${ }^{16}$ Employed Caucasian females are the greatest users of illicit opioids citing chronic pain as the reason for use. Surveyed individuals tend to blame prescription opioids for their opioid addiction and most individuals had at one time legitimate prescriptions, and then turned to illicit opioids because of addiction. For many individuals who started using prescription opioids, they eventually moved towards heroin as a cheaper alternative. In addition, individuals experiencing a drug overdose often had a sentinel event - unexpected events that result in a patient's death or a serious physical or psychological injury.

When pharmacotherapy is used, it may be viewed as a catastrophic problem. If patients are dying from illegal drug use when the medical establishment fails them by withdrawing or minimizing their medically prescribed medication, then some of the burden rests with their health care providers, legislation, and insurance carriers to actively participate in a collegial fashion to achieve parity. ${ }^{17}$ Thus, this opioid epidemic is a complex problem, with multiple parties that have contributed to the problem and therefore, need to be part of the solution. As Sharon Joyce, Director of the Office of the New Jersey Coordinator of Addiction Response and Enforcement Strategies (NJ CARES), states: “it's obviously a multi-faceted problem with multi-faceted type of

\footnotetext{
${ }^{16}$ Engineering National Academies of Sciences et al., Trends in Opioid Use, Harms, and Treatment (National Academies Press (US), 2017), https://www.ncbi.nlm.nih.gov/books/NBK458661/.

${ }^{17}$ Gary W. Jay and Robert L. Barkin, "Perspectives on the Opioid Crisis from Pain Medicine Clinicians," Disease-aMonth: DM 64, no. 10 (October 2018): 451-66, https://doi.org/10.1016/j.disamonth.2018.07.002.
} 
solutions." ${ }^{\prime 18}$ Persons with problematic opioid use are a recognizable group with a high risk of death by opioid overdose whose therapeutic management needs improvement to reduce fatal outcomes. $^{19}$ Different strategies must be developed for identifying and treating nonproblematic opioid use to reduce risk of death. ${ }^{20}$ Thus, this collaborative study explored data to ascertain a deep understanding of the patterns of overdose and establish further research questions to mitigate this problem in Atlantic County, NJ.

\section{Methodology}

As noted above, between the years 2015 to 2017 in Atlantic County, NJ, police, state troopers, and emergency medical personnel who used naloxone to treat opioid overdose victims also collected data on these victims. Information was gathered using the NJ Attorney General's Heroin \& Opiates Task Force Naloxone Administration Reporting Form for Atlantic County (see Appendix A for a copy of that form). The data collected consisted of victim demographics, such as age, gender, and race; as well as the date, time, and location of the overdose. Reactions to the naloxone were also recorded: whether patients responded, how long it took them to respond, and whether the victim survived or not. Forms were completed on 311 overdose victims during the years 2015 to 2017 in Atlantic County, NJ: 32 (10.3\%) in 2015; 136 (43.7\%) in 2016; and 143 $(46 \%)$ in $2017 .^{21}$ The data in its raw form included missing cases, however for the sake of accurate representation, all analysis was based on valid statistics only minus missing cases. While the form included name and birth date, this information was omitted prior to data analysis to maintain the

\footnotetext{
18 "Drug Death in New Jersey Reaches Over 3,000 for the 1st Time." January 9, 2019, WCBS News Radio, https://wcbs880.radio.com/articles/drug-deaths-new-jersey-reach-over-3000-1st-time.

${ }^{19}$ Tara Gomes et al., "Gabapentin, Opioids, and the Risk of Opioid-Related Death: A Population-Based Nested Case-Control Study.," PLoS Medicine 14, no. 10 (October 1, 2017): e1002396.

${ }^{20}$ Christian Rose et al., "Mortality Associated with Opioid Overdose: A Review of Clinical Characteristics and Health Services Received in the Year Prior to Death," Psychiatric Services 70, no. 2 (October 24, 2018): 90-96, https://doi.org/10.1176/appi.ps.201800122.

${ }^{21}$ Note that data collection began midway through 2015.
} 
privacy of the victims. Stockton University Internal Review Board (IRB) approval was obtained to move forward with data analysis.

\section{Research Questions}

Based on the available data provided by the Atlantic County Prosecutor's office on opioid use overdose victims, the following questions were posed by the research team:

RQ1: What are the demographics of the overdose victims in Atlantic County, NJ?

RQ2: What are the number of overdoses, along with survival rates, in Atlantic County, NJ?

RQ3: What is the response time and responsiveness to treatment with naloxone of overdose victims in Atlantic County, NJ?

RQ4: Where and when do overdoses in Atlantic County, NJ take place?

\section{Results}

Research question one focused on the demographics of the overdose victims in Atlantic County. Analysis showed that most opioid overdoses were male (71\%), aged 26-35 (23\%), and Caucasian (72.8\%). 16.2\% were African American, and 10.9\% were Latino. Table 1 below offers frequency distribution with key characteristics for the sample. 
Table 1. Descriptive Statistics Victim Key Demographic Profile $(n=311)$

\begin{tabular}{llll}
\hline \multirow{2}{*}{ Gender } & & $\mathbf{N}$ & $\%$ (valid) \\
\cline { 2 - 3 } Age (yrs.) & Male & 218 & 70.8 \\
& Female & 90 & 29.2 \\
& Missing & 3 & \\
& & & \\
& Less than 25 & 49 & 23.4 \\
& $26-35$ & 70 & 33.5 \\
& $36-45$ & 41 & 19.6 \\
Race & $46-55$ & 36 & 17.2 \\
& Above 55 & 13 & 6.2 \\
Missing & 102 & \\
& & \\
& White & 220 & 72.8 \\
& Black & 49 & 16.2 \\
& Hispanic & 33 & 10.9 \\
\hline
\end{tabular}

Research question number two focused on the number of overdoses, along with survival rates in Atlantic County, NJ. Statistics indicate a marked increase in opioid overdoses and naloxone use from 2015-2017, with most opioid overdoses occurring to individuals using one or two doses of the drug (95.6\%). In Atlantic County, the majority of those who did overdose survived compared to the $6 \%$ that did not. Table 2 below provides specific numbers and percentages on each of these variables. 
Table 2. Victim's Number of Doses and Survival Rate

Number of Doses

$\mathrm{N} \quad \%$ (valid)

\begin{tabular}{llll} 
& 1 & 199 & 73.2 \\
2 & 61 & 22.4 \\
3 & 7 & 2.6 \\
4 & 5 & 1.8 \\
Victim Survival Rate & Missing & 39 & \\
& & & \\
& Did not survive & 17 & 6.0 \\
& Survived & 265 & 94.0 \\
& Missing & 29 & \\
\hline
\end{tabular}

Research question number three focused on the response time and responsiveness to treatment with naloxone of overdose victims in Atlantic County, NJ. Data indicated that in most cases, victims were revived by naloxone in less than 1 to 5 minutes $(62.8 \%)$. About $12 \%$ of the victims responded in under less than a minute. Interestingly, about one-fourth of the cases reported a response time of over 5 minutes, the reasons for which are not clear from the available data. It would be a stretch to make any assumptions about the causes of the response time, including the potential impacts in severe opioid abuse case incidents - something that this study suggests for further examination. Importantly, nearly $82.2 \%$ of those who received naloxone responded to the treatment and presented either an alert or a sedated demeanor. Only about $16 \%$ recorded no response. Table 3 below presents this data. 
Table 3. Response Rate

\begin{tabular}{llll}
\hline \multirow{2}{*}{ Victim Response Behavior } & & $\mathrm{N}$ & $\%$ (valid) \\
\cline { 3 - 4 } & No Response & 30 & 16.1 \\
& Responsive \& Alert & 65 & 34.9 \\
& Responsive but sedated & 88 & 47.3 \\
& Unknown & 3 & 1.6 \\
Authority Response Time & Missing & 125 & \\
& & & \\
& $<1$ min & 27 & 11.9 \\
& $1-3 \min$ & 68 & 30.1 \\
& $3-5$ min & 74 & 32.7 \\
& $>5$ min & 57 & 25.2 \\
& Missing & 85 & \\
\hline
\end{tabular}

Research question four focused on the location and time of overdoses in Atlantic County, NJ. It showed that although overdoses occurred in all months, an upsurge occurred from October to December with 115 overdoses (37\%). January to March saw 43 overdoes (13.9\%); April to June 70 (22.6\%); July to September $82(26.5 \%)$ and October to December, the aforementioned 115 (37.1\%). Keep in mind that data was collected for only a part of 2015, versus the whole years of 2016 and 2017. Therefore, this study does not make a claim about the increase in the victim trend. Still, some clear policy implications emerge for the practitioner groups to enhance their emergency preparedness and appropriate resource allocation to support the victims of opioid abuse during this time of the year particularly. Table 4 below presents this data. 
Table 4. Incident Reporting Pattern by Year and Quarterly Data

\begin{tabular}{llll}
\hline & & $\mathrm{N}$ & $\%$ (valid) \\
\cline { 3 - 4 } Year & & & \\
& 2015 & 32 & 10.3 \\
Incident Months (Quarterly Reporting) & 2016 & 136 & 43.7 \\
& 2017 & 143 & 46.0 \\
& & & \\
& Jan - Mar & 43 & 13.9 \\
& Apr - June & 70 & 22.6 \\
& July - Sep & 82 & 26.5 \\
& Oct - Dec & 115 & 37.1 \\
& Missing & 1 & \\
\hline
\end{tabular}

Next, authors also conducted a bivariate analysis to examine victim's gender association with race, age, and incident month. While none of differences were statistically significant, the patterns warranted elaboration for future research purposes. For example, both white and black females were reported as victims higher than their male counterparts. Hispanic males appeared in larger percentage compared to female Hispanic victims. Next, either younger females (less than 25 years) or older ones (56 and above) appeared to be in higher percentage as victims compared to their male counterpart $(25.4 \%$ vs. $22.7 \%$ and $8.5 \%$ vs. $5.3 \%)$. Lastly, female victims were reported at a greater percentage in the first half (January to June) in comparison to more male victims reported during the latter part of the year (July to August). Table 5 below presents this data. 
Table 5. Bivariate relationship between Race, Gender and Age (\%)

\begin{tabular}{lll}
\hline & Male & Female \\
\cline { 3 - 3 } Race & & 75.0 \\
White & 71.7 & 19.3 \\
Black & 15.1 & 5.7 \\
Hispanic & 13.2 & \\
Age & & \\
Less than 25 & & 25.4 \\
26 - 35 & 22.7 & 33.9 \\
$36-45$ & 33.3 & 15.3 \\
$46-55$ & 21.3 & 16.9 \\
56 and above & 17.3 & 8.5 \\
& 5.3 & \\
Incident Month (Quarterly) & & \\
Jan - Mar & 13.3 & 15.6 \\
Apr - June & 20.2 & 26.7 \\
July - Sep & 28.0 & 23.3 \\
Oct - Dec & 38.5 & 34.4 \\
\hline
\end{tabular}

The authors plotted the Atlantic County data geographically to study the victims' residence location and the incident location. A pattern emerged in the two variables - while most victim's residential addresses were spread across the tri-state area, most opioid abuse incidents were reported from within or near Atlantic City (see Figure 1, below). This analysis calls for further examination to assess the patterns of user's mobility and identify the reasons of the opioid abuse concentration within the region. A more detailed breakdown of the location shows that $54.3 \%$ of overdoses occurred in Atlantic City; 8.4\% in Pleasantville; and 6.1\% in Galloway. However, victims resided across the county; with the largest numbers residing in Atlantic City (15.1\%); Somers Point (4.8\%); Hammonton (4.8\%); and Ventnor (4.5\%). Although only $15.1 \%$ of those who experienced opioid overdoses during 2015-2017 lived in Atlantic City, 53.4\% of the overdoses occurred in Atlantic City (see Appendix B) 

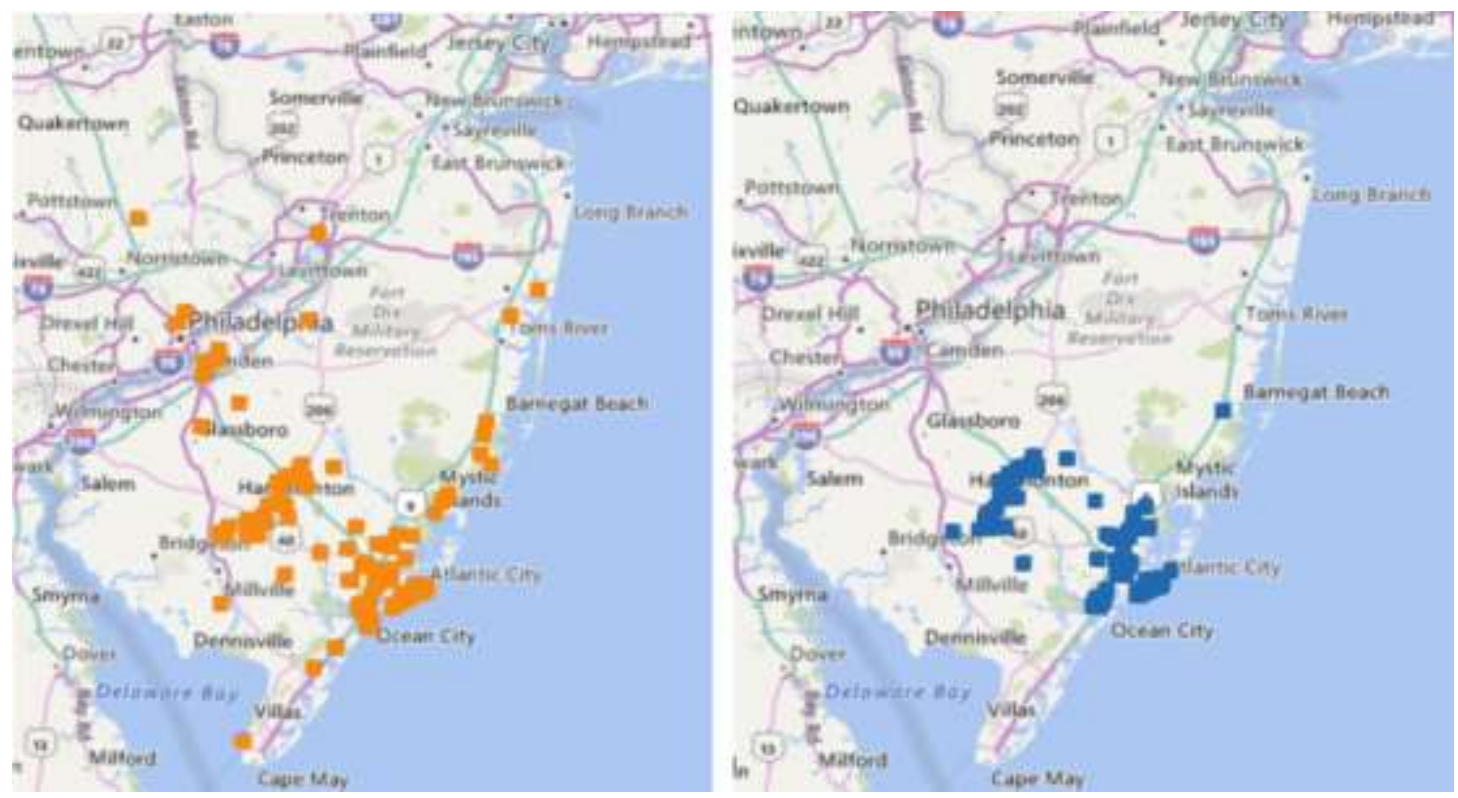

Figure 1. Victim Residential Location (left) vs. Incident Location (right)

\section{Discussion}

The current study of Atlantic County is consistent with statewide statistics that are yielding similar data on this opioid epidemic. In 2018, more than 3,100 people died of drug overdoses in New Jersey; as Angelo Valente, the executive director of Partnership for a Drug-Free New Jersey, states:

This epidemic is impacting every community and it's impacting people of all economic demographics, people in urban communities, people in rural communities, suburbs. Unfortunately, there hasn't been any group of individuals or any area of the state of the country has been spared. ${ }^{22}$

Thus, this data collected by Atlantic County is important to state and local efforts to develop strategies for preventing deaths from opioid overdoses. Specifically, quantifying that there is an increase in opioid overdoses from 2015-2017 in Atlantic Country fits into a state and national pattern. Most overdoses are reported from the white sample, with the largest sample in the age

22 "Drug Death in New Jersey Reaches Over 3,000 for the 1st Time." January 9, 2019, WCBS News Radio, https://wcbs880.radio.com/articles/drug-deaths-new-jersey-reach-over-3000-1st-time. 
range 26-35 (with the other 2 age ranges, 25 and younger and 36-35, still having a significant number of overdoses). Even though the bivariate analysis did not produce statistically significant results, some of the patterns merit discussion and future research is warranted to establish the findings. This study suggested a greater number of white and black females as victims compared to the male population. Similarly, the study found a greater percentage of younger and older female victims than the male counterpart. The descriptive nature of our study does not allow us to pinpoint the reasoning, but it will be critical to evaluate this relationship in future similar research as it may impact specific policy implications.

These findings are key to understanding the epidemic in order to tailor future prevention interventions. Specifically, these demographic findings will help Atlantic County officials concentrate on appropriate local and national research that can lend insight into effective strategies to develop and implement future prevention programs. For example, it will be critical to examine this problem with the intersection of race, age, and gender so appropriate policies can be drawn that suit specific population groups.

Along with identifying individuals who are likely to overdose in Atlantic County, results confirm an increase in the number of opioid overdoses and that the majority of these occur to individuals who use one or two doses of the drug (83.6\%). Fortunately, it also indicates a high survival rate, which could be positively correlated with an increase of naloxone use from 20152017. Similarly, recent research indicates that during the 12 months after a non-fatal overdose, the rate of repeat overdose was 295.0 per 1,000 persons and that of fatal opioid overdose was 1,154 per 100,000 persons. Also, this study showed $64.8 \%$ of patients with nonfatal overdoses 
( $n=75,556)$ had filled opioid prescriptions 180 days before the initial overdose. ${ }^{23}$ This study controlled for age, sex, race/ethnicity, and region, and fatal opioid overdose increased for patients who had filled a benzodiazepine prescription 180 days prior to their initial overdose involving heroin or who required mechanical ventilation at the time of the initial overdose. Unfortunately, the current form does not include information about past drug use and overdoses. This is information that could be useful for a more comprehensive understanding of overdose victims and should be included on the form in the future.

This study suffers from some key limitations. As noted above, the data was collected midway through the year 2015. This means that low numbers of opioid victims from the first year of this study must be taken in that context. Second, this study represents a unique demographic and a snapshot of overdose incidents recorded within this specific time frame and Atlantic County region, thereby limiting cross-generalization to other regions. Third, due to the descriptive nature of the limited data our community partner generated, it limited the ability to develop rigorous statistical models that may have allowed the ability to develop factors explaining the reasons for overdose victimization.

Of the 311 overdose victims, 226 were administered naloxone, and response time and responsiveness were recorded. In most cases, response to overdose victims and treatment with naloxone occurs within the first 5 minutes and almost half had a conscious response. These findings provide positive support for the use of naloxone for overdose victims and are consistent with national research findings. These findings can lend support to the growing evidence that takehome naloxone can prevent opioid overdose in targeted populations. ${ }^{24}$ Increasing accessibility of

\footnotetext{
${ }^{23}$ Mark Olfson et al., "Risks of Fatal Opioid Overdose during the First Year Following Nonfatal Overdose," Drug and Alcohol Dependence 190 (01 2018): 112-19, https://doi.org/10.1016/j.drugalcdep.2018.06.004.

${ }^{24}$ See for example Katzman et al., "An Innovative Model for Naloxone Use Within an OTP Setting."
} 
naloxone, for use at home by friends and family, should be considered at other opioid treatment program settings to reduce opioid overdose deaths.

As noted above, this study's results reveal that although overdoses happened in all months, almost $40 \%$ occurred in October to December. In addition, over half of the overdoses occurred in Atlantic City even though only $15 \%$ of victims reside there. This suggests that Atlantic City is a destination for opioids. These findings are important because consideration of where people live and where they die from an overdose can enhance specific overdose prevention interventions. CDC guidelines for prescribing opioids for chronic pain in the United States indicate that location of overdose and victim's residency can help target places for training, such as training on naloxone administration or rescue breathing. In addition, this information can also be useful to identify health-care professionals in areas with larger numbers of overdose victims. Specifically, educating local prescribers on the CDC's guidelines for prescribing opioids for chronic pain and facilitating better access to medication-assisted treatment with methadone, buprenorphine, or naltrexone can benefit communities with high opioid use disorder rates in the United States. ${ }^{25}$

\section{Future Recommendations}

Based on the conclusions from national research, the data collected in Atlantic County, and the fact that Atlantic County replicates national trends in opiate addiction and overdoses, it is important to explore the feasibility of creating a strategic plan to target the most affected in Atlantic County. Firstly, standards for treating substance use disorders must be in place across Atlantic County and evidence-based models for the prevention and management of prescription drug misuse should be incorporated in medical and health care school curricula.

\footnotetext{
${ }^{25}$ Dowell, Haegerich, and Chou, "CDC Guideline for Prescribing Opioids for Chronic Pain--United States, 2016."
} 
Competencies must be established, equipping interprofessional teams to address prescription drug misuse, and developing materials in pain management and opioid misuse for practicing physicians. This can address a public health emergency in real time. ${ }^{26}$

Perhaps implementation of an outpatient naloxone prescribing policy at a medical center can create a streamlined approach for the interprofessional healthcare team to use in providing naloxone education and improved naloxone access to patients at high risk for opioid overdose. ${ }^{27}$ Ultimately, Atlantic County can design an approach to overdose intervention and treatment aimed at decreasing repeat overdose incidents and facilitating broad-based community education on the causes and effects of opioid use and addiction. Finally, future studies should collect information on the number of overdoses a victim has experienced; if more than one overdose, the length of time in between overdoses; whether the victim overdosed on prescription opiates or "street" product; and if the latter, whether the victim used prescription opiates prior to using "street" products. Ultimately, best-practices in overdose prevention is the goal.

\section{Scroll for Appendix A}

\footnotetext{
${ }^{26}$ Karen H. Antman et al., "Developing Core Competencies for the Prevention and Management of Prescription Drug Misuse: A Medical Education Collaboration in Massachusetts," Academic Medicine: Journal of the Association of American Medical Colleges 91, no. 10 (October 2016): 1348-51, https://doi.org/10.1097/ACM.0000000000001347.

27 Juliana H. Zschoche et al., "Development and Implementation of Procedures for Outpatient Naloxone Prescribing at a Large Academic Medical Center," American Journal of Health-System Pharmacy : AJHP : Official Journal of the American Society of Health-System Pharmacists 75, no. 22 (November 15, 2018): 1812.
} 


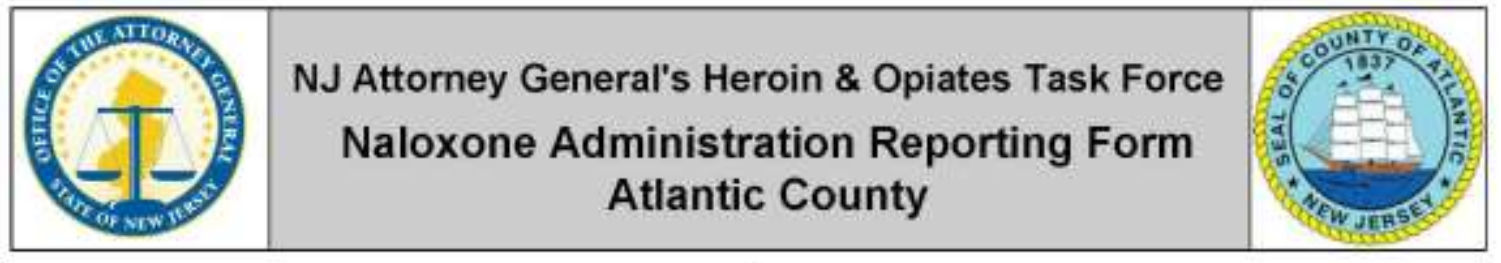

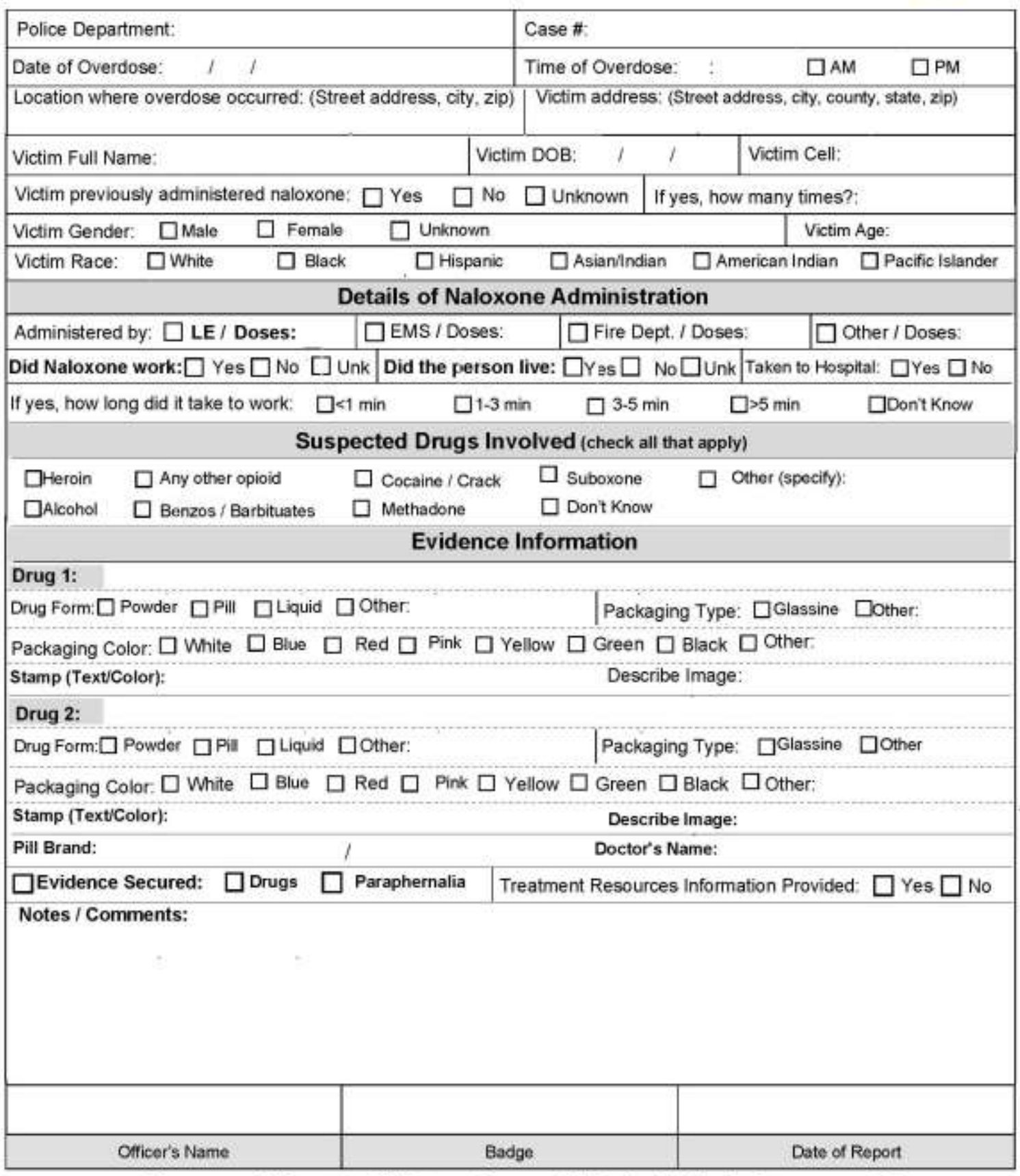

Please email form to DMI@gw.njsp.org AND deshields_b@acpo.org OR fax to 609-530-3650 AND 609-909-7718. 


\section{Appendix B}

\section{Appendix B1. Victim Resident Location}

\begin{tabular}{|c|c|c|}
\hline & $\mathrm{N}$ & $\%$ (valid) \\
\hline Absecon & 1 & 0.6 \\
\hline Eastampton & 1 & 0.6 \\
\hline Egg Harbor City & 1 & 0.6 \\
\hline Egg Harbor Township & 8 & 4.4 \\
\hline Folsom & 2 & 1.1 \\
\hline Galloway & 7 & 3.9 \\
\hline Haddonfield & 1 & 0.6 \\
\hline Hammonton & 15 & 8.3 \\
\hline Kingsland & 1 & 0.6 \\
\hline Landisville & 1 & 0.6 \\
\hline Landsdale & 1 & 0.6 \\
\hline Atlantic City & 47 & 26 \\
\hline Linwood & 3 & 1.7 \\
\hline Little Egg Harbor & 3 & 1.7 \\
\hline Manahawkin & 3 & 1.7 \\
\hline Margate & 3 & 1.7 \\
\hline Mays Landing & 3 & 1.7 \\
\hline Millville & 1 & 0.6 \\
\hline Morristown & 1 & 0.6 \\
\hline Mount Laurel & 1 & 0.6 \\
\hline Nesco & 1 & 0.6 \\
\hline Northfield & 3 & 1.7 \\
\hline Barnegat & 1 & 0.6 \\
\hline Oaklyn & 1 & 0.6 \\
\hline Ocean City & 3 & 1.7 \\
\hline Philadelphia & 2 & 1.1 \\
\hline Pleasantville & 9 & 5 \\
\hline Point Pleasant & 1 & 0.6 \\
\hline Roper & 1 & 0.6 \\
\hline Seaville & 1 & 0.6 \\
\hline Sewell & 1 & 0.6 \\
\hline Somers Point & 15 & 8.3 \\
\hline Toms River & 1 & 0.6 \\
\hline Trenton & 1 & 0.6 \\
\hline Tuckerton & 1 & 0.6 \\
\hline
\end{tabular}




\begin{tabular}{lll} 
Upper Twp & 1 & 0.6 \\
Ventnor & 14 & 7.7 \\
Villas & 1 & 0.6 \\
Vineland & 5 & 2.8 \\
Williamstown & 1 & 0.6 \\
Berlin & 1 & 0.6 \\
Buena Vista & 8 & 4.4 \\
Cherry Hill & 1 & 0.6 \\
Deer Park & 1 & 0.6 \\
Dorothy & 1 & 0.6 \\
Belmar & 1 & 0.6 \\
Total & 181 & 100 \\
Missing & 130 & \\
\hline
\end{tabular}

Table B2. Victim Incident Location

\begin{tabular}{lll}
\hline & Frequency & $\%$ (valid) \\
\cline { 2 - 3 } Absecon & 2 & 0.6 \\
Atlantic City & 169 & 54.9 \\
Barnegat & 1 & 0.3 \\
Brigantine & 1 & 0.3 \\
Buena Vista & 10 & 3.2 \\
Dorothy & 1 & 0.3 \\
Egg Harbor Township & 3 & 1 \\
Folsom & 5 & 1.6 \\
Galloway & 19 & 6.2 \\
Gloucester Township & 1 & 0.3 \\
Hammonton & 16 & 5.2 \\
Landisville & 1 & 0.3 \\
Linwood & 3 & 1 \\
Nesco & 1 & 0.3 \\
Pleasantville & 26 & 8.4 \\
Port Republic & 2 & 0.6 \\
Somers Point & 27 & 8.8 \\
Ventnor & 17 & 5.5 \\
Vineland & 2 & 0.6 \\
Williamstown & 1 & 0.3 \\
Total & 308 & \\
Missing & 3 & \\
\hline
\end{tabular}


Merydawilda Colón, Ph.D., LSW, is the Executive Director of the Stockton Center for Community Engagement and a Professor of Social Work at Stockton University.

Tara Crowell, Ph.D., is a Professor of Public Health and Program and Internship Coordinator at Stockton University.

Carra Leah Hood, Ph.D., is the Associate Provost at Stockton University and an Associate Professor of Writing.

MaryLou Galantino, PT, MS, PhD, MSCE, FAPTA, is a Distinguished Professor of Physical Therapy at Stockton University.

Manish Madan, Ph.D., is an Associate Professor of Criminal Justice at Stockton University.

The authors would like to thank Captain Bruce K. DeShields, who works in the Atlantic County Prosecutor's Office, Litigation Division / Crisis Negotiations Unit. 